\title{
A GESTÃO DE DOCUMENTOS NOS ARQUIVOS ACADÊMICOS E A PORTARIA MEC N $N^{\circ} .1 .224 / 2013$
}

\section{A GESTIÓN DE DOCUMENTOS EN EL ARCHIVO ACADÉMICO Y ORDENANZA MEC $n^{\circ} .1 .224 / 2013$}

\author{
João Arlindo dos Santos Neto - santosneto@uel.br \\ Doutorando no Programa de Pós-Graduação em Ciência da \\ Informação da Universidade Estadual Paulista \\ (UNESP/Marília). Professor Colaborador do Departamento de \\ Ciência da Informação da Universidade Estadual de Londrina
} (UEL).

Rosana Pereira dos Santos - zanasantos25@gmail.com Especialista em Gestão de Arquivos e Tecnologias Aplicadas pela Universidade Estadual de Londrina (UEL).

\section{RESUMO}

Introdução: Discute a gestão de documentos nos arquivos acadêmicos universitários, a partir das orientações que a Portaria MEC $n^{\circ} .1 .224 / 2013$ propõe aos Institutos Federais de Ensino Superior.

Objetivo: Verifica e analisa se a gestão documental do acervo acadêmico de graduação das Instituições de Ensino Superior da cidade de Londrina/PR está em consonância com a referida portaria.

Metodologia: Apresenta uma pesquisa qualitativa de caráter descritivo, a partir de uma revisão bibliográfica, e também, exploratória para analisar as atividades desenvolvidas no setor de arquivo acadêmico das Instituições de Ensino Superior, valendo-se de uma coleta de dados utilizando o questionário.

Resultados: Constata a necessidade de uma gestão eficaz com os documentos armazenados no arquivo, para prestar à sociedade um atendimento de qualidade, com base na rapidez e na confiabilidade das informações solicitadas.

Conclusões: Conclui que as Instituições de Ensino Superior agem ainda, de acordo com a rotina administrativa diária, sem se fazer valer de uma legislação arquivística.

Palavras-chave: Gestão de Documentos. Acervo Acadêmico. Instituição de Ensino Superior. Legislação Arquivística. Portaria nº 1.224/2013. 


\section{INTRODUÇÃO}

No Brasil há um grande número de Instituições de Ensino Superior (IES) nos âmbitos públicos, federais e particulares, o que gera um grande volume documental em seus arquivos, em especial, nos acadêmicos.

As IES exercem grandes funções tanto no ambiente acadêmicoadministrativo quanto no setor técnico-administrativo, elas são grandes geradoras de documentos. Em recente pesquisa realizada pelo Censo 2013 e publicada no final do ano de 2014, no período compreendido entre os anos de 1995 a 2007, são 2,4 mil IES existentes no Brasil, sendo 301 públicas e 2 mil particulares. "As universidades são responsáveis por $53,4 \%$ das matrículas, enquanto as faculdades concentram 29,2\%." (PORTAL BRASIL, 2014).

Em decorrência ao crescimento das matrículas, cresce também, o número de vagas ofertadas por curso, e por consequência, os documentos gerados pelas IES e recebidos pelos novos ingressantes como: cópias de documentos pessoais, histórico escolar, certificados, entre outros. É perceptível o aumento das solicitações que corroboram para o crescimento no volume dos documentos produzidos e recebidos pela instituição, tornando difícil a organização, recuperação e localização nos arquivos gerados para cada processo. Esta dificuldade se dá também pela falta de mão de obra qualificada, para realizar atividades como localizar, arquivar e descartar de forma correta os documentos.

Após a permanência e conclusão no curso, os alunos deixam de retirar documentos pessoais como (diploma ou histórico escolar, certificados de cursos realizados, entre outros), por diferentes razões, fazendo com que o arquivo acomode esses documentos. Acredita-se que esse fato ocorre por diversos motivos: à desistência ou trancamento do curso, mudança de município, falecimento, entre outros. Tendo em vista também esse cenário, o Arquivo Nacional promoveu encontros entre as IES para discutirem e adotarem critérios de melhorias para a 
organização do volume documental produzido a partir dos documentos acadêmico-administrativos e dos arquivos técnico-científicos (VENÂNCIO, 2014). Abriu-se espaço para discussões, encontros e troca de experiências, tais ações foram empreendidas com a sistematização e criação de arquivos em diversas universidades.

Devido à necessidade das IES disporem de instrumento de gestão de arquivos, em 2006, o Arquivo Nacional realizou o I Workshop com as Instituições Federais do Ensino Superior (IFES) para dialogar sobre a classificação, a temporalidade e a destinação dos documentos de arquivos (BOTTINO, 2014). Outra iniciativa que também teve origem no Arquivo Nacional foi à criação da Portaria MEC no. 1.224 de 18 de dezembro de 2013, publicada no Diário Oficial da União (D.O.U.) que "Institui normas sobre a manutenção e guarda do Acervo Acadêmico das Instituições de Educação Superior (IES) pertencentes ao sistema federal de ensino." (BRASIL, 2013). Esta portaria é a base para a melhoria na aplicabilidade dos instrumentos de gestão de arquivos, priorizando as normas constantes no Código de Classificação de Documentos e da Tabela de Temporalidade e Destinação de Documentos de Arquivos, voltados para o acervo acadêmico. Além de manter 0 acervo organizado, indica condições adequadas de conservação e instruções para o fácil acesso a consulta.

O acervo acadêmico das IES é composto por um conjunto de documentos gerados a partir das atividades desenvolvidas dentro dos setores administrativos, relativos ao processo de entrada do aluno, o período de permanência na universidade (processos, solicitação de documentos, etc.) até a conclusão do curso realizado.

Acredita-se que ao seguir a Portaria $n^{0} .1 .224 / 2013$ assegura-se à IES: a agilidade na recuperação da informação dos documentos; o compartilhamento de dados, para prestar informações aos setores ou autoridades pertinentes, a organização do acervo acadêmico permanente e a destinação correta aos documentos que já cumpriram o prazo de guarda aprovado pela própria IES. 
O objetivo da pesquisa foi verificar e analisar se o tratamento documental do acervo acadêmico de graduação das IES da cidade de Londrina/PR está em consonância com os requisitos da Portaria MEC $n^{\circ}$. 1.224/2013. Analisou-se o arquivo geral da secretaria acadêmica de uma instituição privada e de uma federal. No decorrer da pesquisa foi discutido sobre gestão de documentos, seus conceitos e suas etapas. Descreveu-se, também, de forma breve, sobre os arquivos acadêmicos universitários e a Portaria $n^{\circ}$. 1.224/2013 e sua aplicabilidade no acervo das IES.

\section{ARQUIVOS ACADÊMICOS UNIVERSITÁRIOS}

Os arquivos acadêmicos universitários contemplam os documentos gerados e recebidos pela comunidade interna da instituição. No entanto, normalmente, eles se dividem em dois tipos, o das instituições universitárias e das universidades que tem como função: o ensino, a pesquisa e a extensão; e o dos centros universitários, que se caracterizam pela oferta qualificada do ensino, mas não precisam manter atividades de pesquisa e possuem autonomia para criar cursos ou vagas. Nesta pesquisa, o foco foi 0 arquivo das instituições universitárias.

As universidades possuem em sua estrutura, órgãos e setores importantes, que contribuem para o seu crescimento e desenvolvimento. No setor administrativo, dentre outros departamentos, destaca-se o arquivo acadêmico, como fonte de memória da própria instituição. Ele é composto por documentos que servem como subsídios para o desenvolvimento das atividades de ensino, pesquisa e extensão, bem como para a vida acadêmica do aluno. A preocupação quanto à organização dos arquivos gerados pelas instituições é explicitada no seguinte discurso: 
[...] na ausência de documentos e arquivos bem organizados e administrados, as instituições não podem funcionar eficazmente. Elas não só passam por problemas e falta de continuidade na administração, como têm de, freqüentemente, suplementar documentos locais através de fontes externas de informação. (EVANS, 1994, p. 9).

A partir desses problemas, as IES estão optando pela implantação de sistemas internos de arquivos, com 0 intuito de administrar todo o ciclo documental, que contempla sua produção, uso e destinação, de modo a estabelecer a organização em seus arquivos.

O tema "arquivos universitários" ainda vem sendo estudado e debatido por parte da comunidade arquivística, mas ainda assim, há pouca literatura especializada sobre 0 assunto. Os arquivos universitários estão em processo de desenvolvimento, buscando suas bases conceituais e sustentação teórica (BOSO et al., 2007).

A preocupação voltada aos arquivos universitários se deu, no Brasil, a partir da realização do $1^{\circ}$ Seminário Nacional de Arquivos Universitários, promovido pela Coordenadoria do Sistema de Arquivos da Universidade Estadual de Campinas (UNICAMP). Segundo Bottino (2014) este seminário, marcou a história dos arquivos universitários no País, passando a ser área de debate específica no campo da Arquivologia. Com o objetivo de promover encontros, trocar experiências, conhecimentos, criar e sistematizar os arquivos para universidades, intensificar estudos e pesquisas, como também, de elaborar o censo dos arquivos universitários brasileiros e conhecer a realidade dos acervos universitários, foi criado em 1996 o Comitê de Arquivos Universitários, vinculado à Associação dos Arquivistas Brasileiros (AAB). Com o passar do tempo, essas iniciativas deram continuidade e permaneceram ativas, com a retomada do Grupo de Estudos da UNICAMP (SIARQ/UNICAMP).

De acordo com Bottino (1994, p. 67) os arquivos universitários podem ser definidos como: 
O conjunto de documentos, tanto institucionais quanto privados, produzidos, recebidos e acumulados por estabelecimento de ensino superior no curso da gestão jurídica-acadêmica-administrativa que servem de suporte informacional e prova de evidência no exercício de suas funções, constituindo a memória institucional.

As IES são grandes geradoras de documentos, principalmente daqueles advindos das atividades do ensino, pesquisa e extensão, que necessitam ser tratados e geridos, pois os registros dessas atividades ficam armazenados nos arquivos dessas instituições.

Bottino (2014, p. 22) afirma que

[...] a missão primária do arquivo universitário é a de preservar a herança documental da instituição, que se amplia uma vez que ele extrapola os limites do campus universitário, com atividades e serviços prestados. Assim tem por missão a gestão de documentos que comporta as duas vocações do arquivo, incidindo sobre os acervos produzidos e recebidos pela instituição [...].

Os acervos acadêmicos possuem como missão, portanto, custodiar e preservar a memória da instituição, a partir da gestão de documentos. Nesses ambientes podem-se encontrar informações importantes para a sociedade, pois neles está caracterizada a vida acadêmica de um sujeito e, muitas vezes, um documento contido na pasta de um aluno ou ex-aluno pode ser considerado como prova judicial.

Segundo Bottino (2014) a criação do arquivo universitário é um trabalho difícil, que requer a conscientização da universidade em relação à preservação e manutenção de seus arquivos, e do quão importante esse ambiente é para o alcance dos objetivos institucionais e sociais da própria IES. A criação e manutenção do arquivo universitário é uma necessidade, e acredita-se também, ser obrigatoriedade de toda instituição, pois o fluxo de informação é abundante e, assume-se a função não apenas de organizar os documentos, mas também, de 
disseminá-los para seu público alvo. Deste modo, discute-se na próxima seção o tema enfocado no presente artigo, gestão de documentos.

\section{GESTÃO DE DOCUMENTOS}

A gestão de documentos é considerada como um conjunto de procedimentos de registro e controle dos trâmites dos documentos, em que se organiza a informação, torna o acesso mais rápido e proporciona o gerenciamento dos prazos de guarda e descarte. Para Bernardes (1998, p.11) a gestão de documentos refere-se a um:

Conjunto de medidas e rotinas que garante o efetivo controle de todos os documentos de qualquer idade desde sua produção até sua destinação final (eliminação ou guarda permanente), com vistas à racionalização e eficiência administrativas, bem como à preservação do patrimônio documental de interesse histórico-cultural.

A gestão de documentos torna-se um elemento essencial para as instituições, pois, atua desde a produção do documento até o descarte deles ou guarda permanente, isto é, implica diretamente no ciclo de vida dos documentos. Esta atividade também visa preservar o patrimônio histórico e cultural de uma determinada instituição.

A aplicação da gestão de documentos em arquivos, além de garantir a documentação das políticas e atividades governamentais, garante a reunião de documentos de valor permanente, uma boa organização dos documentos e a constituição do patrimônio arquivístico de um país (JARDIM, 1987). Sobretudo, possibilita uma economia considerável à instituição assim como o controle da informação.

A Divisão do Programa de Informação Geral da Organização das Nações Unidas para a Educação, a Ciência e a Cultura (UNESCO), com o intuito de agregar valor aos assuntos relevantes aos profissionais da informação, nas áreas especializadas de gerenciamento de registros e arquivos administrativos, desenvolveu ao longo dos anos o Programa - 
RAMP (Records Archives Management Program) idealizado por James Rhoads (JARDIM, 2007). Este programa possui elementos básicos que buscam refletir os temas gerais discutidos na atualidade e incluem, assim, projetos, estudos e outras atividades destinadas a:

- Produção: concepção e gestão de formulários, preparação e gestão de correspondência, gestão de informes e diretrizes, fomento de sistemas de gestão de informação e aplicação de tecnologias modernas a esses processos;

- Utilização e Conservação: criação e melhoramento dos sistemas de arquivos e de recuperação de dados, gestão de correio e telecomunicações, seleção e uso de equipamento reprográfico, análise de sistemas, produção e manutenção de programas de documentos vitais e uso de automação e reprografia nestes processos;

- Destinação: a identificação e descrição das séries documentais de programas de avaliação e destinação de documentos, arquivamento intermediário, eliminação e recolhimento dos documentos de valor permanente as instituições arquivísticas. (RHOADS, 1983 apud JARDIM, 2007).

Entre os elementos que o RAMP busca para apresentar soluções no gerenciamento de arquivos, destaca-se a produção, utilização e conservação, e a destinação, explicitados anteriormente.

Outro fator a ser destacado, refere-se a implicação direta que a gestão de documentos exerce no ciclo de vida dos mesmos, a gestão possibilita um controle eficiente da redução dos documentos produzidos e recebidos no decorrer das atividades, que visam à eficácia, economia e a qualidade dos documentos independentemente de seu suporte.

A gestão de documentos é composta por atividades imprescindíveis para o arquivista, que são fundamentais para o controle das informações, desde sua criação até sua destinação final, qualquer que seja sua origem, idade, natureza ou suporte.

Rousseau e Couture (1998) mencionam a criação, avaliação, aquisição, conservação, classificação, descrição e comunicação. Dentre estas atividades, neste artigo, são discutidas três delas: a classificação, a descrição e a avaliação. 
A classificação refere-se ao tratamento dado aos documentos de uso corrente, ou seja, aqueles que possam ser mais rapidamente encontrados quando solicitados. Ela é fundamental à eficiência da administração de documentos correntes, bem como para todos os aspectos que envolvem o controle de documentos, pois, se estes forem bem classificados possivelmente atenderão as necessidades das operações correntes (SCHELLENBERG, 2006).

Esta etapa antecede todas as outras, visa analisar e identificar o conteúdo do documento e se materializa num instrumento denominado Plano de Classificação ${ }^{1}$ ou Código de Classificação. A classificação é definida também pelo dicionário terminológico como "Ato ou efeito de analisar e identificar o conteúdo de documentos, selecionar a categoria de selecionar a categoria de assunto sob a qual sejam recuperados, podendo-se Ihes atribuir códigos." (ARQUIVO NACIONAL, 2005, p. 49).

A partir do exposto pode-se afirmar que a classificação de documentos auxilia e facilita a localização de documentos das operações advindas da fase corrente, independente de sua forma ou suporte, produzido por pessoa física ou decorrente de documentos rotineiro da instituição.

Outra etapa da gestão de documentos que pode iniciar durante a classificação de documentos é a descrição arquivística, entendida como uma ferramenta criada pelo arquivista para descrever um documento. Em consonância com a classificação de documentos este instrumento quando elaborado, facilita o processo de busca da informação, porém essa etapa em sua maioria é realizada após a classificação de documentos.

O Arquivo Nacional (2005, p. 67) define a descrição arquivística como um "Conjunto de procedimentos que leva em conta os elementos formais e de conteúdo dos documentos para elaboração de

\footnotetext{
1 "Esquema de distribuição de documentos em classes, de acordo com métodos de arquivamento específicos, elaborado a partir do estudo das estruturas e funções de uma instituição e da análise do arquivo por ela produzido." (ARQUIVO NACIONAL, 2005, p.132).
} 
instrumentos de pesquisa." Nesta prática, os documentos são descritos de acordo com sua estrutura, natureza física e classificação, observando sua autoria, tipo, título e estrutura (SCHELLENBERG, 2006).

Alerta-se que a descrição é uma atividade de suma importância para um arquivo, pois sem ela,

[...] corre-se o risco de criar uma situação análoga à do analfabeto diante de um livro, que ele pode pegar e folhear, mas ao qual não pode ter acesso completo por não possuir meios que the permitam compreender a informação. A classificação arquivística, desprovida das atividades de descrição, somente é inteligível para as pessoas que organizaram o acervo. (LOPEZ, 2002, p. 12).

Compreende-se que as práticas de descrição apresentam-se condição sine qua non para uma boa classificação arquivística, visto que elas permitem a compreensão e interpretação da maneira como o acervo foi organizado.

A Câmara Técnica de Normalização de Descrição Arquivística (CTNDA) criada em 1991 pelo Conselho Nacional de Arquivos (CONARQ, 1991), pela Portaria $n^{\circ} 56$ de setembro de 1991, tem por finalidade propor normas, em conformidade com as normas internacionais, que fossem discutidas pela comunidade profissional. Aprovadas pelo CONARQ e adotadas como normas brasileiras, elas são conhecidas como a Norma Brasileira de Descrição Arquivística NOBRADE (ARQUIVO NACIONAL, 2005).

Este conjunto de normas para a descrição arquivística faz parte de um processo que visa:

Assegurar a criação de descrições consistentes, apropriadas e auto-explicativas; Facilitar a recuperação e a troca de informação sobre documentos arquivísticos; Possibilitar o compartilhamento de dados de autoridades; Tornar possível a integração de descrições de diferentes arquivos num sistema unificado de informação. (CIA, 2001, p. 1). 
Infere-se que a NOBRADE tem como objetivo assegurar a elaboração de descrições bem fundamentadas, tornar a recuperação e a troca de informação dos documentos arquivísticos mais fácil, tornar possível o compartilhamento dos dados de autoridade dos documentos e permitir a integração dos dados de descrição de diversos arquivos.

Simultaneamente à classificação e a descrição de documentos arquivísticos, outra etapa é desenvolvida na gestão de documentos, a avaliação. Esta deve incidir nos documentos produzidos no exercício de uma mesma função ou atividade, ser efetuada por grupo ou comissões denominados pela instituição, composta por profissionais que possuam o conhecimento das atividades e da estrutura organizacional.

Para Paes (1986, p. 25) "A avaliação é um processo de análise da documentação de arquivos, visando estabelecer a sua destinação de acordo com seus valores probatórios e informativos." É uma etapa decisiva no processo de desenvolvimento de implantação de políticas de gestão de documentos, em instituições públicas ou privadas, pois consiste em analisar o ciclo de vida dos documentos, identificar valores e definir prazos de guarda e de eliminação independentemente do suporte que é apresentado.

Segundo Schellenberg (2006, p. 227) "A avaliação de documentos não deve se basear em instituição ou em suposições arbitrárias de valor. Deve ser, ao contrário, baseada na análise total da documentação relativa ao assunto a que se referem os documentos em questão." Esta prática, portanto, não pode ser influenciada por arbitrariedades ou imposições institucionais, mas ser realizada de acordo com a documentação a ser avaliada.

A instituição que compõe uma comissão de avaliação garante aos órgãos os benefícios (objetivos) de uma avaliação corretamente elaborada, tais como:

[...] redução na massa documental; agilidade na recuperação dos documentos e das informações; eficiência administrativa; melhor conservação dos 
documentos de guarda permanente; racionalização da produção e do fluxo de documentos (trâmite); liberação do espaço físico e incremento à pesquisa. (BERNARDES, 1998, p. 15).

A partir do exposto, percebe-se que vários são os benefícios de uma avaliação bem planejada e executada, entre eles destaca-se a redução do volume documental e liberação do espaço físico necessário para armazenar os documentos, uma das maiores preocupações das instituições e organizações.

Verificou-se que a gestão de documentos depende de inúmeros fatores para garantir a recuperação das informações, pois necessita do uso de metodologias, normas e, também, legislações.

As etapas descritas precisam ser pensadas de acordo com as especificidades de cada arquivo, pois, os arquivos, diferentemente, não seguem outras áreas, como a biblioteconomia, por exemplo, que segue um padrão de classificação, disponível na tabela de Classificação Decimal Dewey. Os arquivos são únicos, cada IES possui um sistema interno de arquivo, que não pode ser comparado ao modo de gestão de outro.

Tendo em vista esse contexto, legislações arquivísticas foram pensadas e instituídas para que os processos e práticas arquivísticas pudessem ser mais bem executados. A seguir, discutem-se as questões presentes na Portaria MEC $\mathrm{n}^{\circ}$. 1.244/2013, que visa à melhoria da gestão documental nos arquivos.

\section{PORTARIA MEC $\mathrm{n}^{\circ} \cdot \mathbf{1 . 2 4 4 / 2 0 1 3}$}

A Legislação Arquivística Brasileira é composta por um conjunto de instrumentos legais que possuem a finalidade de consolidar as ações voltadas para os documentos de arquivos, públicos ou privados, e também dispõem sobre a prática da gestão de documentos nesses ambientes. 
O CONARQ, órgão vinculado ao Arquivo Nacional do Ministério da Justiça disponibiliza e atualiza anualmente as normativas relativas aos arquivos, que tem por objetivo "[...] a política nacional de arquivos públicos e privados, bem como exercer orientação normativa visando à gestão documental e à proteção especial aos documentos de arquivo." (BRASIL, 2002).

$\mathrm{Na}$ tentativa de atender os requisitos necessários para o gerenciamento dos arquivos acadêmicos das instituições de ensino superior, foi criada a Portaria $n^{0} .1 .224$ de 18 de dezembro de 2013, que institui normas sobre a manutenção e guarda do acervo acadêmico das Instituições de Educação Superior (IES) pertencentes ao Sistema Federal de Ensino. De acordo com o artigo primeiro da portaria, competem as IFES aplicarem todas as normas constantes no Código de Classificação de Documentos de Arquivo relativos às atividades-fim e da Tabela de Temporalidade e Destinação de Documentos de Arquivo relativos às atividades-fim.

É definido também na portaria, que o acervo acadêmico será composto de documentos e informações definidos no Código e na Tabela, devendo a IFES obedecer a prazos de guarda, destinações finais e observações previstas na tabela. Não somente as IFES, mas qualquer organização necessita agir em conformidade com os dispositivos legais que se referem ao seu campo de atividade, buscar atender normalizações prescritas nesses instrumentos se faz necessário.

Dentre os elementos constantes na referida portaria, destaca-se que: Se vencido o prazo de guarda, o documento cuja sua destinação seja o descarte, a IES poderá substituir o documentos físico do acervo por documentos devidamente microfilmados; as atualizações do Código e da Tabela devem substituir automaticamente a versão constante do anexo da portaria; a guarda e conservação dos documentos pelas IES devem ser permanentemente organizados e em condições adequadas de conservação, ser de fácil acesso e prontos para consulta; as 
consultas e visitas poderão ser realizadas a qualquer tempo pela Comissão Própria de Avaliação (CPA); as visitas de Órgãos e Agentes poderão ser feitas a qualquer tempo pelos órgãos e agentes públicos atuantes para fins de regulação, avaliação e supervisão; a manutenção e guarda do acervo não condizente com os prazos de guarda, destinações finais e observações, poderá ser caracterizada como irregularidade administrativa (BRASIL, 2013).

A Portaria também propõe aos gestores de arquivos acadêmicos o Código de Classificação de Documentos Relativos a Atividades-Fim das Instituições e a Tabela de Temporalidade e Destinação de Documentos, com períodos pré-estabelecidos para a guarda dos documentos. Bottino (2014, p. 26) afirma que "A definição dos prazos e destinação final dos documentos é uma atividade muito complexa, que requer uma análise profunda não só da legislação, como também dos valores inerentes ao documento." Os arquivos acadêmicos precisam passar por uma exaustiva análise, com a aprovação e conhecimento dos responsáveis pela manutenção e guarda do acervo acadêmico, atentando-se para as diretrizes que os dispositivos legais apresentam quanto a gestão dos documentos.

\section{PRODECIMENTOS METODOLÓGICOS}

A pesquisa objetivou verificar e analisar se a gestão documental do acervo acadêmico de graduação das IES de Londrina/PR está em consonância com os requisitos da Portaria MEC n. 1.224/2013. Quanto à tipologia da pesquisa apresenta-se como exploratória e como método utilizou-se a pesquisa de campo, como instrumento para coleta de dados utilizou-se o questionário com questões abertas e fechadas. $A$ abordagem do problema se deu de maneira qualitativa.

$O$ universo desta pesquisa constituiu-se de duas IES da cidade de Londrina, sendo uma federal e uma privada. A população do estudo foram dois gestores, um de cada IES. 
Verificou-se a estrutura, os materiais, a quantidade de funcionários, a rotina $\mathrm{e}$ as atividades desenvolvidas nos acervos acadêmicos. Compararam-se as diretrizes da Portaria com a realidade apresentada pelas IES, com o intuito de averiguar se elas estão de acordo com os requisitos exigidos pela referida portaria. Foi questionado também se as IES conhecem a portaria em questão e, se estão seguindo o Código de Classificação e Tabela de Temporalidade de Documentos propostos na Portaria. A análise dos dados foi realizada de forma comparativa, a partir das respostas obtidas através do questionário aplicado aos gestores das IES selecionadas.

\section{RESULTADOS E DISCUSSÃO}

A IES de caráter privada possui um profissional arquivista atuando como gestor do acervo e conta com a colaboração de mais três funcionários. A IES do setor público, não possui um arquivista como gestor do acervo, conta apenas com o apoio de um colaborador com formação em nível superior, mas não na área de Arquivologia, e mais quatro colaboradores. Ambos os arquivos desenvolvem as atividades de: recebimento, armazenamento, busca, protocolo, empréstimo, entre outras.

Em relação ao arquivamento dos documentos, o respondente da IES federal afirmou ser realizado com pastas suspensas. Já na IES privada o participante respondeu que o arquivamento envolve várias etapas que vão desde o recebimento do documento pelo setor de protocolo até seu arquivamento de fato, no entanto, não descreveu quais seriam essas etapas.

De acordo com as duas IES, os documentos componentes da pasta do aluno baseiam-se na documentação pessoal, histórico escolar, certificado de ensino médio, documentos de transferência, análise curricular e outros produzidos no decorrer da vida acadêmica do aluno. 
Quanto à forma de inserção dos documentos no sistema eletrônico do arquivo, a IES federal possui um banco de dados em que as informações são inseridas sobre os documentos recebidos, enquanto a IES privada ao receber a documentação, a digitaliza via scanner e a insere no Sistema de Gerenciamento Eletrônico (GED).

No questionamento sobre a procura por documentos antigos no acervo das IES, ambas afirmaram receber solicitações do protocolo semanalmente, podendo ser de uma a duas vezes por semana.

Ao questionar como as IES realizam as buscas de documentos antigos e qual o período de retorno que a instituição dá ao solicitante, a IES federal utiliza-se do nome do aluno, sem se preocupar com os homônimos, e o prazo estabelecido para entrega dos documentos é de no máximo 05 dias. A IES privada realiza as buscas através do sistema interno implantado, mapeando o cadastro do processo do aluno o que facilita a entrega do documento no dia.

Em relação ao instrumento utilizado no tratamento dos documentos mais antigos, como a descrição e a avaliação, a IES pública informou possuir um tratamento diferenciado dado aos documentos antigos, mas não discorreu sobre ele. Já a IES privada mencionou que não dispõe de um instrumento nas práticas de descrição e avaliação. Entende-se que os instrumentos de pesquisa têm como objetivo permitir ao gestor de arquivo acessar e controlar o fluxo dos documentos, deixando o arquivo organizado. "Um arquivo sem os instrumentos de pesquisa adequados corre o risco de se tornar um verdadeiro mistério para os usuários." (LOPEZ, 2002, p. 10).

Foi questionado se os gestores dos arquivos conheciam, utilizavam e aplicavam as normas da portaria pesquisada e ambos respondentes afirmaram que conhecem e utilizam as normas estabelecidas na portaria.

Indagou-se a opinião dos gestores se as prescrições da portaria deveriam ser estendidas e requeridas a todas as IES, e não somente para as federais, como um modelo padrão a ser seguido nos acervos 
acadêmicos. O gestor da IES federal acredita ser útil padronizar, pois todos os arquivos utilizariam a mesma legislação, o que facilitaria e padronizaria os processos arquivísticos. O gestor da IES privada também concorda que deve ser utilizada como padrão, pois facilitaria também nos critérios de avaliação dos cursos.

Ao perguntar se as IES possuem Código de Classificação e Tabela de Temporalidade próprios, o respondente da IES pública afirma que sim, porém, ainda não o aplica no acervo acadêmico, enquanto o da IES privada afirma que também possui, mas que os aplicam no acervo. Já em relação a atualização dessas ferramentas, o gestor da IES federal deixou de responder a questão, enquanto o da IES privada afirmou que a atualização acontece sempre que é preciso destinar os fins dos documentos.

Ao solicitar aos respondentes requisitos necessários para um tratamento com maior eficiência que o realizado atualmente, o da IES federal manteve sua observação no que já é praticado, referindo-se em manter os arquivos organizados por curso e nome do aluno. Por outro lado, o sujeito da IES privada acredita não ser necessário realizar alteração no tratamento documental atual, visto que ele entende como suficiente $\mathrm{o}$ atendimento da demanda e atende os requisitos da portaria.

Quanto ao critério utilizado pelas IES ao arquivar os documentos permanentes e as formas utilizadas para localizá-los posteriormente, as duas IES utilizam métodos parecidos. A federal insere os dados numa planilha destinada ao arquivo permanente e nele os documentos são numerados sequencialmente (número do arquivo e da pasta no arquivo) e armazenados em caixa arquivo. A privada retira as pastas dos alunos do arquivo deslizante e são acondicionados e cadastrados em caixas arquivo de polionda e armazenados em estantes.

O último questionamento referiu-se ao artigo segundo da portaria, isto é, se as IES mantém permanentemente organizado e armazenado os documentos de maneira a permitir acesso rápido e fácil. As duas IES 
foram pontuais em dizer que sim, mas nenhuma delas complementou a resposta.

Após a comparação das respostas obtidas pelos questionários, ficou evidente que as IES conhecem ou já ouviram falar da Portaria $n^{\circ}$. 1.224/2013. Constatou-se também que as IES não seguem fielmente as normas estabelecidas da Portaria por entender que as atividades desenvolvidas atualmente, suprem as necessidades da comunidade interna e externa da instituição.

\section{CONCLUSÃO}

Os números de arquivos acadêmicos têm crescido exponencialmente junto ao aumento do número de IES no Brasil, o volume gerado por esses arquivos é imenso e precisa ser bem gerido.

A gestão de documentos contribui em todas as etapas para os acervos acadêmicos, ela reflete na organização eficaz, no acesso, na eficiência da recuperação pela informação contida no documento, no controle da massa documental, na preservação dos documentos de forma permanente, entre outros benefícios.

Constatou-se que as IES pesquisadas estão ainda restritas às rotinas administrativas, fazendo com que deixem de consultar as normas das regulamentações sobre arquivos, mesmo obtendo o conhecimento parcial ou na íntegra dos instrumentos legais.

Nas IES analisadas, certas rotinas relativas à organização dos acervos acadêmicos correspondem à apenas, alguma cláusula da Portaria. A partir das respostas apresentadas pelos questionários, compreende-se que as IES utilizam pouco das normas da Portaria MEC $n^{\circ} 1.224 / 2013$.

O tratamento documental na IES federal não se dá quanto à gestão de documentos como parâmetro de rotinas, que possa garantir um controle efetivo dos documentos acadêmicos. A IES privada utiliza- 
se da gestão de documentos em parte, já que conta com sistema GED implantado, facilitando o tratamento do documental.

Evidencia-se que as IES não utilizam de instrumentos de pesquisas adequados, sugeridos pela literatura apresentada, a fim de auxiliar no acesso, controle, orientação e localização dos documentos. No entanto, os gestores sugerem que a Portaria deva ser seguida como um modelo padrão, para que todas as IES utilizem a mesma linguagem verbal e Código de Classificação e Tabela de Temporalidade.

Acredita-se que as instituições precisam seguir as prescrições da Portaria, pois são evidentes os benefícios não só para a própria instituição, como também para a sociedade, a comunidade acadêmica e aos gestores de arquivos. Entre os benefícios, destacam-se cinco: 1) Tratamento documental adequado e de qualidade, dentro das normas instituídas pelos órgãos regulatórios, dispensados aos dossiês acadêmicos, pois estes representam o histórico acadêmico dos alunos; 2) O reconhecimento dos arquivistas ou gestores de arquivos, ao serem nomeados detentores de acervos, assumindo assim a responsabilidade da organização do acervo frente à IES e ao Ministério da Educação; 3) Manter padronizado o uso do Código de Classificação de Documentos e da Tabela de Temporalidade; 4) Facilitar o trabalho do arquivista quando houver tombamento de documentos, ou seja, a necessidade de assumir o acervo de outra IES, por motivos de descredenciamento ou encerramento de suas atividades; e, 5) Prestar à sociedade um atendimento de qualidade, com base na rapidez e na confiabilidade das informações solicitadas, quando organizadas de forma eficiente.

Conclui-se que as IES pesquisadas agem ainda, de acordo com a rotina administrativa diária, sem se fazer valer da legislação arquivística brasileira, o que faz com que seus processos arquivísticos sejam demorados e desprovidos de embasamento legal e, consequentemente, tornem custosos e não valorizados os serviços ali desenvolvidos. 


\section{REFERÊNCIAS}

ARQUIVO NACIONAL. Dicionário brasileiro de terminologia arquivística. Rio de Janeiro: Arquivo Nacional, 2005.

BERNARDES, leda Pimenta. Como avaliar documento de arquivo. São Paulo: Arquivo do Estado Imprensa Oficial, 1988.

BOSO, A. K. et al. A importância do arquivo universitário. Revista ACB: Biblioteconomia em Santa Catarina, Florianópolis, v. 12, n. 1, p. 123131, jan./jun. 2007.

BOTTINO, Mariza. Arquivo universitário: considerações em torno da questão. Panorama da situação no Brasil. Rio de Janeiro, 1994, 203 f. Dissertação (Mestrado em Ciência da Informação), Universidade Federal do Rio de Janeiro/instituto Brasileiro em Informação em Ciência e Tecnologia, 1994.

. Arquivo universitário: sonho ou realizada? In: VENÂNCIO, Renato; NASCIMENTO, Adalson. Universidades \& Arquivos: gestão, ensino e pesquisa. Belo Horizonte: Fino Traço, 2014. p. 21-32.

BRASIL. Decreto No 4.073, de 3 de janeiro de 2002. Regulamenta a Lei no 8.159 , de 8 de janeiro de 1991, que dispõe sobre a política nacional de arquivos públicos e privados. Diário Oficial da União [da Casa Civil da Presidência da República], Brasília, DF, 04 jan. 2002, p. 1.

. Portaria MEC n 1224 de 18 de dezembro de 2013, Institui normas sobre a manutenção e guarda do Acervo Acadêmico das Instituições de Educação Superior (IES) pertencentes ao sistema federal de ensino. Diário Oficial da União [da Casa Civil da Presidência da República], Brasília, DF, n. 246, 19 dez. 2013. Seção 1, p. 105-116.

CIA. Isad(G) Norma geral internacional de descrição arquivística. Rio de Janeiro: Arquivo Nacional, 2001.

CONARQ. Conselho Nacional de Arquivos. 2014. Disponível em: <http://www.conarq.arquivonacional.gov.br/cgi/cgilua.exe/sys/start.htm?s id=4> Acesso em: 23 abr. 2015.

CONARQ. Lei № 8159 de 08 de janeiro de 1991, Dispõe sobre a política nacional de arquivos públicos e privados. Arquivo Nacional, Rio de Janeiro, dez. 2014. 
EVANS, Frank B. Princípios fundamentais para um enfoque global da administração de arquivos e documentos. Arquivo e Administração, Rio de Janeiro, v. 15, p. 5-11, 1994.

JARDIM, José Maria. O conceito e a prática de gestão de

documentos. Rio de Janeiro: Acervo, 1987.

Sistemas e políticas públicas de arquivo no Brasil. Niterói:

Universidade Federal Fluminense, 2007.

LOPEZ, André Porto Ancona. Como descrever documentos de arquivo: Elaboração de instrumentos de pesquisa. São Paulo: Arquivo do Estado, 2002.

PAES, Marilena Leite. Arquivo Teoria e Prática. Rio de Janeiro: Fundação Getúlio Vargas, 1986.

PORTAL BRASIL. Ensino superior registra mais 7,3 milhões de estudantes. 2014. Disponível em:

http://www.brasil.gov.br/educacao/2014/09/ensino-superior-registramais-de-7-3-milhoes-de-estudantes . Acesso em: 15 fev 2015.

ROUSSEAU, Jean-Yves; COUTURE, Carol. Os fundamentos da disciplina arquivística. Lisboa: Dom Quixote, 1998.

SCHELLENBERG, Theodore R. Arquivos Modernos: princípios e técnicas. 3. ed. Rio de Janeiro: FGV, 2006.

VENÂNCIO, Renato. Arquivos universitários no Brasil: esboço de uma cronologia. In: VENÂNCIO, Renato; NASCIMENTO, Adalson.

Universidades \& Arquivos: gestão, ensino e pesquisa. Belo Horizonte: Fino Traço, 2014. p. 33-48.

\section{Title}

A document management in the archives academic and ordinance MEC $n^{\circ}$. $1.224 / 2013$

\section{Abstract}

Introduction: Discusses document management on university academic files from the guidelines that the MEC Ordinance No. 1.224 / 2013 proposes to Federal Institutes of Higher Education.

Purpose: Checks and analyzes the document management of the academic undergraduate assets of higher education institutions in the city of Londrina / $\mathrm{PR}$ is in line with that ordinance.

Methodology: Presents a qualitative research of descriptive character, from a literature review, and also to analyze the exploratory activities in the academic 
file sector of higher education institutions, making use of a data collection using the questionnaire.

Results: Confirmed the need for effective management with documents stored in the file, to provide the company a quality service based on the speed and reliability of the information requested.

Conclusions: Concludes that the higher education institutions still act, according to the daily administrative routine, not to enforce an archival legislation.

Keywords: Document Management. Academic collection. Institution of higher education. Archival legislation. Ordinance MEC n. 1.224/2013.

\section{Titulo}

A gestión de documentos en el archivo académico y ordenanza MEC $n^{\circ}$. $1.224 / 2013$

\section{Resumen}

Introducción: La gestión de documentos Discute sobre expedientes académicos universitarios de las directrices que el MEC Ordenanza No $\mathrm{N}^{\circ} .224$ / 2013 propone Institutos Federales de Educación Superior.

Objectivo: Los cheques y los análisis de la gestión de documentos de los activos de grado académico de las instituciones de educación superior en la ciudad de Londrina / PR está en línea con la ordenanza.

Metodología: Presenta una investigación cualitativa de carácter descriptivo, a partir de una revisión de la literatura, y también para analizar las actividades de exploración en el sector expediente académico de las instituciones de educación superior, haciendo uso de una recopilación de datos mediante el cuestionario.

Resultados: Confirma la necesidad de una gestión eficaz con los documentos almacenados en el archivo, para proporcionar a la empresa un servicio de calidad basado en la velocidad y la fiabilidad de la información solicitada.

Conclusiones: Conclui que las instituciones de educación superior siguen actuando, de acuerdo a la rutina administrativa diaria, no para hacer cumplir una legislación archivística.

Palabras clave: Gestión de documentos. Acervo académico. Institución de educación superior. Legislación Archivo. Ordenanza MEC n. 1.224/2013.

Recebido em: 15/03/2015

Aceito em: 10/09/2015 